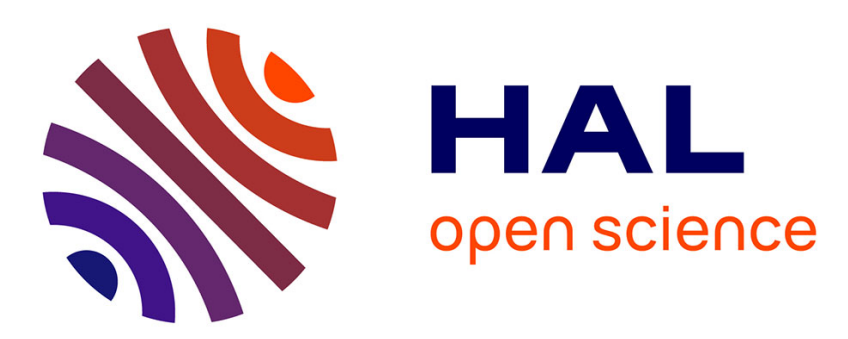

\title{
A bicyclic unit reversal to stabilize the 12/14-helix in mixed homochiral oligoureas
}

\author{
Pierre Milbeo, Matthieu Simon, Claude Didierjean, Emmanuel Wenger, \\ Emmanuel Aubert, Jean Martinez, Muriel Amblard, Monique Calmès, \\ Baptiste Legrand
}

\section{To cite this version:}

Pierre Milbeo, Matthieu Simon, Claude Didierjean, Emmanuel Wenger, Emmanuel Aubert, et al.. A bicyclic unit reversal to stabilize the 12/14-helix in mixed homochiral oligoureas. Chemical Communications, 2020, 56 (57), pp.7921-7924. 10.1039/d0cc02902e . hal-03080580

\section{HAL Id: hal-03080580 https://hal.science/hal-03080580}

Submitted on 17 Dec 2020

HAL is a multi-disciplinary open access archive for the deposit and dissemination of scientific research documents, whether they are published or not. The documents may come from teaching and research institutions in France or abroad, or from public or private research centers.
L'archive ouverte pluridisciplinaire HAL, est destinée au dépôt et à la diffusion de documents scientifiques de niveau recherche, publiés ou non, émanant des établissements d'enseignement et de recherche français ou étrangers, des laboratoires publics ou privés. 


\title{
A bicyclic unit reversal to stabilize the $12 / 14$-helix in mixed homochiral oligoureas
}

\author{
Pierre Milbeo ${ }^{\mathrm{a}}$, Matthieu Simon ${ }^{\mathrm{a}}$, Claude Didierjean $^{\mathrm{b}}$, Emmanuel Wenger $^{\mathrm{b}}$, Emmanuel Aubert ${ }^{\mathrm{b}}$, Jean Martinez ${ }^{\mathrm{a}}$, Muriel \\ Amblard $^{\mathrm{a}}$, Monique Calmès ${ }^{\mathrm{a}^{*}}$, Baptiste Legrand ${ }^{\mathrm{a}^{*}}$
}

aIBMM, Univ Montpellier, CNRS, ENSCM, Montpellier, France

bUniversité de Lorraine, CNRS, CRM2, Nancy, France

The insertion of cyclic building blocks in oligoureas to stabilize or modulate the properties of the 12/14-helix was often fruitless. We herein propose a fully compatible highly constrained building block that could be incorporated into oligoureas to develop highly stable and functionnal oligoureas helices.

Peptidomimetic foldamers, differing from $\alpha$-peptides by the addition of at least one atom in the peptide backbone, can mimic the structural and functional properties of biopolymers. They are interesting candidates for biological applications, as catalysts and in the field of materials. ${ }^{1}$ The development of a wide range of $\beta-, \gamma$ - or $\delta$-amino acids and the design of oligomers with heterogeneous backbones result in a high diversity of helical structures. ${ }^{2}$ Besides, the use of peptidomimetic $\gamma$-building blocks owning an additional heteroatom in the backbone led to the construction of oligomers such as oligoureas. ${ }^{3}$ They exhibit particular folding properties mainly related to the ability of the urea link to form bifurcated hydrogen bonds..$^{2 c, 3 e-1}$ The group of Guichard has first shown that they adopt a $12 / 14$-helix stabilized by hydrogen bonding network forming 12- and 14-membered pseudocycles. ${ }^{3 e-i}$ More recently, they have demonstrated that helical structures are also obtained from hybrid peptides combining urea/amide or urea/carbamate bonds. ${ }^{4}$ Furthermore, robust helical structures can be achieved by conformational restriction of the building blocks using cyclic units as mainly described in $\beta$ - and $\gamma$-peptide foldamers. ${ }^{2 b, 5}$ Nevertheless, incorporation of appropriate constrained cyclic residues in oligoureas is challenging and only few examples are reported in the literature. Our group has first demonstrated that short homo-oligourea sequences based on Bicyclic Amino Carbamoyl units (BAC units, derived from the (S)-2aminobicyclo[2.2.2] octane carboxylic acid, [(S)-ABOC]) ${ }^{6}$ (Fig. 1), lead to a highly stable $12 / 14$-helix both in solution and in the solid state. ${ }^{7}$ No trans/cis isomerization urea bond was detected in solution for the (S)-BAC homo-oligoureas whereas it occurs for oligoureas derived from acyclic $\beta^{3}$-amino acids. ${ }^{3 \mathrm{~h}}$ Then, it has been reported that replacement of the central residue of an acyclic oligourea pentamer by a chiral cis-1,2diaminocyclohexane residue slightly enhances helix stabilization, while the use of the corresponding trans residue compromises the helical folding. ${ }^{8,9}$ Later, we reported on the synthesis of mixed oligoureas alternating $(S)$ - and $(R)$-BAC units with acyclic $\beta^{3}$-amino acid derivatives, i.e. (S)-N-(2aminopropyl)carbamoyl (APC) and (S)-N-(2-amino-3phenylpropyl)carbamoyl (APPC) units, in order to elaborate robust and versatile oligoureas (Fig. 1a,b). ${ }^{10}$ Unfortunately, extensive structural analyses revealed that the homochiral $S / S$ sequences did not fold, while the corresponding heterochiral $R / S$ sequences led to a distorted left-handed 12/14-helix with solvent molecules intercalated in its bifurcated hydrogen-bond network.

In this piece of work, we have modified the substitution pattern of the bicycle by reversing its orientation within oligoureas using the chiral (S)-1,2-diaminobicyclo [2.2.2] octane motif [(S)-DABO] recently developed in our group (Fig. 1a). ${ }^{11}$ Therefore, the synthesis of the mixed oligoureas can be reversed, allowing the permutation of the bridgehead position and the 2-position in the final molecule, compared to previously synthesized oligoureas based on the $A B O C$ residue (Fig. 1b). In this orientation, we hypothesized that the reverse Bicyclic Amino Carbamoyl unit [(S)-rBAC] derived from the (S)-DABO could share similar torsion angle values and signs in the mixed $(S)-r B A C /(S)-A A C$ oligoureas inducing canonical mixed oligourea helices. Thus, we report here the synthesis and the extensive structural characterization of oligoureas alternating the (S)$r B A C$ and (S)-AAC residues. We tentatively rationalized the folding behaviours of this class of oligoureas incorporating the (S)-BAC, (R)-BAC and (S)-rBAC bicyclic units using density functional theory (DFT) calculations. 
(a)

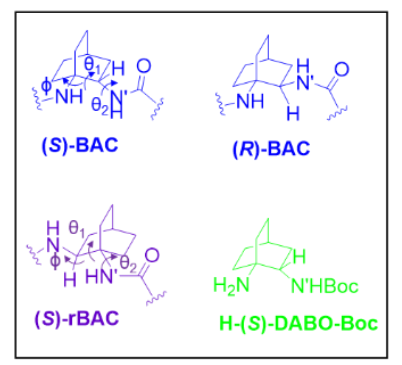

(c)

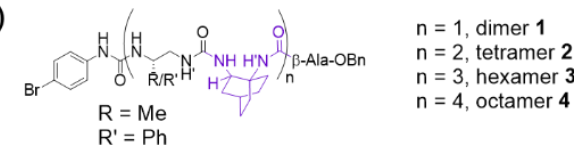

(b)

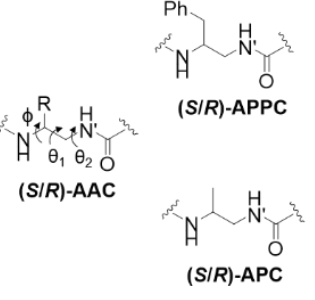<smiles>CCCCNC(=O)NC(=O)Nc1ccc(Br)cc1</smiles>
(S)-AAC

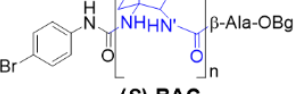
(S)-BAC

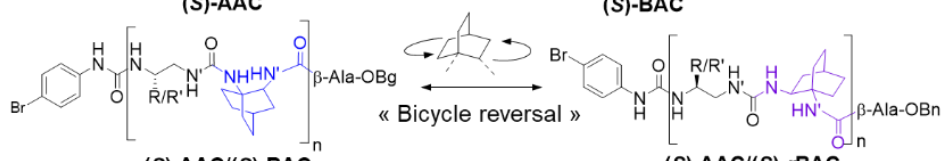

(S)-AAC/(S)-BAC

$(S)-A A C /(S)-r B A C$

(SIR)-APC

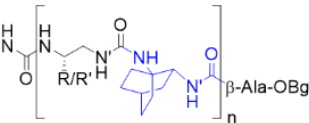

(d)

(S)-AAC/(R)-BAC

$$
\text { Boc-APC-OSu Boc-APPC-OSu Cyclic urea }
$$

Fig 1. (a) Monomeric units and torsion angles nomenclature. (b) General oligourea sequences based on $(S)$-BAC (in blue), $(R)$-BAC (in red) and ( $S$ )-AAC residues, $(S$ )$r B A C$ (in green) and (S)-AAC motifs. (c) Sequences of (S)-rBAC-containing oligoureas 1-4. (d) Chemical structures of succinimidyl carbamate derivatives of $\beta^{3}$-amino acids (Boc-APC-OSu and Boc-APPC-OSu), and cyclic byproducts derivatives (cyclic urea, i.e. allophanate) and cyclic biuret).

We used stepwise solution-phase method to prepare four oligoureas 1-4 (Fig. 1c, Scheme S1) of different lengths alternating (S)-rBAC and (S)-AAC residues. The first coupling was performed by adding an equimolar amount of $\mathrm{H}$-(S)-DABO-Boc (Fig. 1a) to the succinimidyl carbamate of $\mathrm{H}-\beta-\mathrm{Ala}-\mathrm{OBn}$ (SuO-CO$\beta$-Ala-OBn) in the presence of $\mathrm{N}, \mathrm{N}$-diisopropylethylamine (DIEA). Chain elongation was achieved by successive Boc removal, trifluoroacetic acid (TFA) salt neutralization, and urea bond formation using alternatively acyclic and cyclic residues (see Scheme S1 in the SI for full details). Succinimidyl carbamate derivatives Boc-APC-OSu and Boc-APPC-OSu (Fig. 1d), ${ }^{12}$ were used to introduce acyclic residues. The (S)-rBAC unit was correctly incorporated using freshly activated $\mathrm{H}-(S)$-DABO-Boc with the DSC reagent under optimized conditions that limited formation of the by-product (i.e. cyclic biuret, Fig. 1d) by limiting the activation time, and by repeating the coupling step until completion of the reaction (detailed procedure available in SI).

We first assessed the conformational preferences of the newly synthesized oligoureas 1-4 recording their $C D$ spectra in $\mathrm{CH}_{3} \mathrm{OH}$ at $20^{\circ} \mathrm{C}$. All compounds shared the characteristic signature of the oligoureas right-handed 12/14-helix with a strong positive maximum around $205 \mathrm{~nm}$ (Fig. 2a). These results indicated that homochiral mixed oligoureas alternating (S)-rBAC and (S)-AAC motifs might adopt right-handed 12/14-helices in solution. Such hypothesis was stressed using NMR spectroscopy in $\mathrm{CD}_{3} \mathrm{OH}$ and DMSO- $d_{6}$. We first assigned nearly all resonances of the compounds 2-4 combining COSY, TOCSY and ROESY spectra (Tables S1-7 and Fig. S4-11). The ${ }^{3} J\left(\mathrm{NH},{ }^{\alpha} \mathrm{CH}\right)$ coupling constants of the (S)-rBAC and (S)-AAC residues in the oligomers were characteristic of an antiperiplanar arrangement with average values of $9.5 \pm 0.7 \mathrm{~Hz}$ and $9.5 \pm 0.6 \mathrm{~Hz}$ in $\mathrm{CD}_{3} \mathrm{OH}$ and DMSO- $d_{6}$, respectively (Table S8). Moreover, we measured large chemical shift differences between the diastereotopic ${ }^{\alpha} \mathrm{CH}_{2}$ protons of the central acyclic residues APC2 and APPC4, i.e. $\Delta \delta\left({ }^{\alpha} \mathrm{CH}_{2}\right)>1.0 \mathrm{ppm}$ (Table S9) and found a dozen of typical $\mathrm{i}, \mathrm{i}+2$ and $\mathrm{i}, \mathrm{i}+3$ medium and long range NOE cross-peaks, which are fully compatible with the right-handed 12/14-helical fold (Fig. 2b) in both solvents. Such evidences indicated that (S)$r \mathrm{BAC} /(\mathrm{S})$-AAC oligoureas adopted a stable 12/14-helix in $\mathrm{CD}_{3} \mathrm{OH}$ in agreement with the $C D$ data, but also in the chaotropic DMSO- $d_{6}$. When we used a complete set of NOEs as distance restraints for the NMR structure calculation of hexamer $\mathbf{3}$, the resulting 15 lowest-energy conformations exhibited a welldefined right-handed 12/14-helix (rmsd value of $0.44 \AA$ on the backbone heavy atoms) stabilized $\mathrm{C}=\mathrm{O}(\mathrm{i}) \cdots \mathrm{HN}(\mathrm{i}+1)$ and $\mathrm{C}=\mathrm{O}(\mathrm{i}) \cdots \mathrm{HN}^{\prime}(\mathrm{i}+2)$ hydrogen bonds (Fig. 2b). Importantly, highresolution crystals structures tetramer $\mathbf{2}$ and octamer $\mathbf{4}$ suitable for X-ray diffraction (XRD) were obtained by slow evaporation of methanol solutions. Both asymmetric units consisted of one oligourea, which adopted a canonical right-handed 12/14-helix with 2.5 residues per turn and a pitch around $5.1 \AA$ (Fig. $2 \mathrm{c}$ and S13-14). The average backbone dihedral angle values in the $(S)$ $r \mathrm{BAC} /(\mathrm{S})-\mathrm{AAC}$ oligourea solid-state structures were $\phi=-101 \pm$

Fig. $\mathbf{2}$ (a) CD spectra of $\mathbf{1}$ (plain line), $\mathbf{2}$ (dashed line), $\mathbf{3}$ (dash-dotted line) and $\mathbf{4}$ (dotted line) recorded at $20^{\circ} \mathrm{C}$. The absolute values of the $\mathrm{CD}$ positive maxima (in deg. $\mathrm{cm}^{2} . \mathrm{dmol}^{-1}, \lambda=205 \mathrm{~nm}$ ) of the homo-(S)-BAC and (S)-rBAC/(S)-AAC oligoureas are indicated in the right corner. (b) Characteristic non-sequential backbone/backbone and backbone/side chain NOE cross-peaks detected both in $\mathrm{CD}_{3} \mathrm{OH}$ and DMSO- $d_{6}$. Superimposition of the 15 lowest energy NMR solution structures of hexamer 3. (c) Crystal structures of $\mathbf{2}$ and $\mathbf{4}$. The (S)-AAC residues are in yellow. The hydrogen bonds are shown in yellow dashed lines. (a)

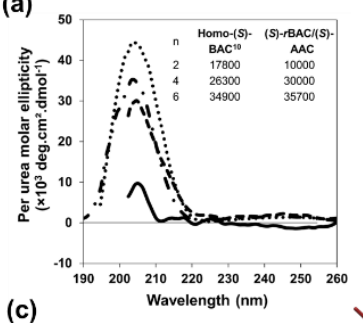

(b) NOE correlations:

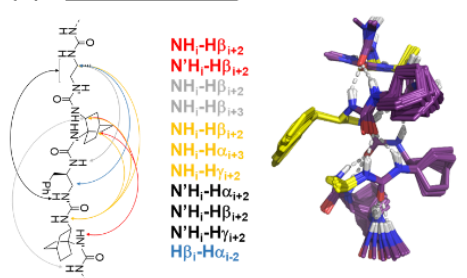

$\mathrm{H} \beta_{i}-\mathrm{H \alpha}_{\mathrm{i}-2}$ (c)

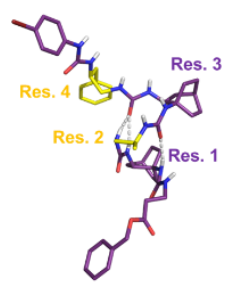

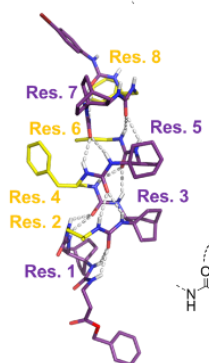

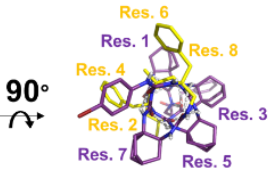

Hydrogen bonds network:

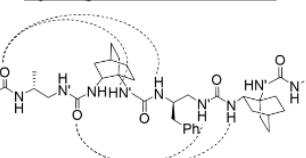


$6^{\circ}, \theta_{1}=57 \pm 5^{\circ}$ and $\theta_{2}=72 \pm 8^{\circ}$ when the last residue torsion angle values were omitted. Such values were very close to those reported for the canonical oligourea 12/14-helix composed of acyclic $\beta^{3}$-amino acid derivatives ${ }^{3 h}$. The backbone structures of the canonical (S)-AAC octamer (ccdc75017) and the mixed (S)$r B A C /(S)-A A C$ oligourea 4 were well superimposed as shown in Fig. 3a (the RMSD value of the backbone heavy atoms was 0.86 $\AA$ ). The main structural deviations between compounds $\mathbf{2}$ and $\mathbf{4}$ occurred at both terminal parts, which are key areas for the crystal packing. The extremities linked the oligomers in a head to tail fashion as previously observed in oligourea crystal structures $^{3 \mathrm{~h}, 7}$ (Fig. S15).

We then compared the relative stability of the $(S)-r B A C /(S)$ AAC oligourea helix to the (S)-AAC and (S)-BAC homooligoureas, and heterochiral mixed $(R)-\mathrm{BAC} /(S)-\mathrm{AAC}$ helices. As previously described, ${ }^{3 f, 7,10}$ the signal intensity at $205 \mathrm{~nm}\left(\theta_{205}\right)$ increased with the oligomer's length and only a slight and reversible decrease was observed when the temperature rose to $55^{\circ} \mathrm{C}$ (Fig. S3). The weak thermal loss of structure was fully reversible and the oligomer's stability increased with their lengths. Few NOEs could be detected on the ROESY spectrum of 1 indicating that it should be disordered or highly flexible. In agreement, $\theta_{205}$ was about twice less weak for 1 than for the (S) -BAC dimer $\left(\theta_{205}=10 \times 10^{3}\right.$ and $17.8 \times 10^{3}$ deg.cm ${ }^{2} \cdot \mathrm{mol}^{-1}$, respectively) that was able to initiate a $12 / 14$ turn with only two units $^{7}$. Nevertheless, it is worth noting that compound $\mathbf{3}$ and the (S)-BAC hexamer shared comparable maxima values, $\theta_{205} \sim 35 \times 10^{3}$ deg.cm ${ }^{2} \cdot \mathrm{mol}^{-1}$ (while a maximum at $27 \times 10^{3}$ deg. $\mathrm{cm}^{2} \cdot \mathrm{mol}^{-1}$ was reported for an acyclic oligourea hexamer) 10. Thus, the $(S)-r B A C /(S)-A A C$ 1:1 pattern shared a comparable stability with the $(S)$-BAC helix exclusively composed of bicyclic units. The bicycle bridgehead steric hindrance prevented the trans/cis isomerization of the adjacent urea bond. We detected only $\mathrm{N}^{\prime} \mathrm{H}(\mathrm{i})-\mathrm{H} \beta(\mathrm{i}+1)$ NOEs assigned to trans/cis isomerization of the urea bonds preceding the AAC residues.

Finally, we tentatively rationalized why the 12/14-helix could fully accommodate the $r(B A C)$ residue in homochiral oligoureas thanks to DFT calculations and a close analysis of the optimized structures. First, it is worth noting that the BAC residue imposed a steric unfavourable (-)-synclinal conformation to the $(S)$-acyclic residues with a $\theta_{1}$ backbone torsion angle average value of $-56^{\circ}$, while a $(+)$-synclinal arrangement around the main chain $\mathrm{C}-\mathrm{C}$ bonds was typically observed for the $\beta^{3}, \gamma^{4}$-peptides and the acyclic oligourea canonical helix. ${ }^{3 e-1}$ Homochiral 12/14-helices models with similar parameters were built, i.e. (S)-BAC/(S)-AAC and (S)$r \mathrm{BAC} /(\mathrm{S})-\mathrm{AAC}$, and optimized at the B3LYP-D3/6-31G(d,p) level of theory (detailed protocol available in $\mathrm{SI}$ ). Calculations converged toward stable helices in vacuum and the structural deviations were very slight between the initial and the optimized helices (the torsion angles did not vary significantly, Fig. S16-17). Interestingly, the theoretical study was in good agreement with the experimental data. The $(S)-r B A C /(S)-A A C$ was the most stable helix (Table S11). The disordered (S)$\mathrm{BAC} /(S)-\mathrm{AAC}$ oligourea had significantly higher energy when it

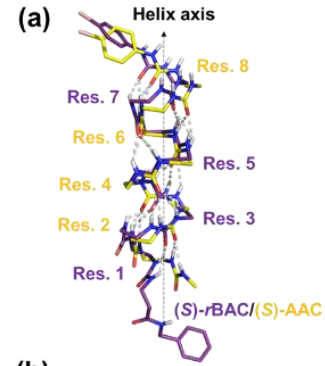

(b)

(S)-rBAC/(S)-AAC right-handed 12/14 helix

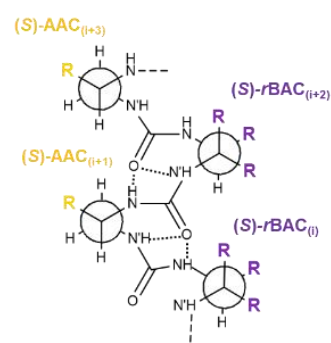

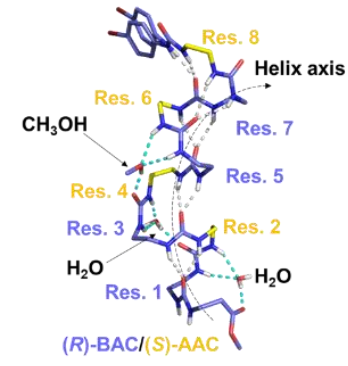

(S)-BAC/(S)-AAC right-handed $12 / 14$ helix

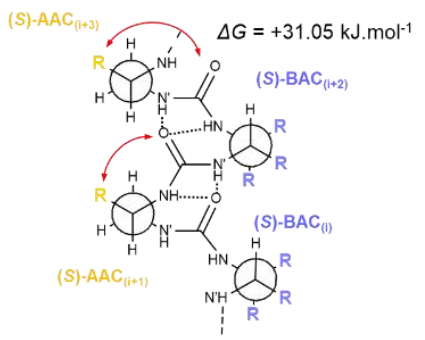
Fig 3. (a) Superimposition of the crystal structures of the (S)-AAC (ccdc75017, in
yellow) and mixed (S)-rBAC/(S)-AAC oligourea octamers (4, in purple) (left panel). Crystal structure of the mixed heterochiral $(R)$-BAC/(S)-AAC oligourea octamer (right panel). (b) Schematic representation of the homochiral 12/14-helix models optimized by DFT. Steric clashes due to non-ideal configuration and atoms promiscuity was indicated as red arrows.

was optimized as a $12 / 14$-helix single conformer $(\Delta G=+31.05$ $\left.\mathrm{kJ} . \mathrm{mol}^{-1}\right)$. A close inspection of the models showed that various steric effects involved the AAC side chains (Fig. 3). In the (S)$r B A C /(S)$-AAC helix, these latter were in optimal equatorial position while they were virtually projected in axial within the heterochiral oligourea, generating strong steric clashes with the adjacent backbone carbonyls. In both $(S)$ and $(R)$-BAC/(S)-AAC, the side chains were projected in inadequate intermediate positions, which prevented the folding of the homochiral $(S)$ $\mathrm{BAC} /(S)$-AAC oligourea, but could be accommodated in the $(R)$ $\mathrm{BAC} /(S)$-AAC helix. ${ }^{10}$ In this latter, the local crowding was offset by the insertion of solvent molecules in its bifurcated hydrogen bonds, which significantly bent its axis while the helical structure of compounds $\mathbf{2}$ and $\mathbf{4}$ was ideally straight (Fig. 3).

In summary, a high content of $r \mathrm{BAC}$ ( $1: 1$ pattern) could be incorporated without altering the 12/14-helix structure while increasing its stability compared to oligourea helices composed solely of highly constrained bicyclic residues. Furthermore, the $r \mathrm{BAC}$ incorporation locked the urea bond beside the bicycle bridgehead in trans configuration. However, the minimal content of bicyclic units to be incorporated in acyclic oligoureas for a maximum stabilization of the 12/14-helix remains to be determined. Interestingly, such incorporation in functional oligoureas would be valuable to tune their properties.

The authors thank the "Laboratoire de Mesure Physique" (LMP) of the university of Montpellier, the SCBIM and "Université de Lorraine" for NMR spectroscopic and XRD facilities. The EXPLOR mesocentre is also thanked for providing access to computing facility (project 2019CPMXX0984/wbg13). There are no conflicts to declare. 


\section{References}

1 As selected reviews and article, see : (a) R. P. Cheng, S. H. Gellman and W. F. DeGrado, Chem. Rev., 2001, 101, 3219-3232; (b) D. J. Hill, M. J. Mio, R. B. Prince, T. S. Hughes and J. S. Moore, Chem. Rev. 2001, 101, 3893-4011; (c) D. Seebach, A. K. Beck and D. J. Bierbaum, Chem. Biodiversity, 2004, 1, 1111-1238; (d) C. Baldauf, R. Günther and H. J. Hofmann, Biopolymers, 2005, 80, 675-687; (e) D. Seebach, D. F. Hook and A. Glättli, Biopolymers (Peptide Science), 2006, 84, 23-37; D. Seebach, J. Gardiner, Acc. Chem. Res. 2008, 41, 1366-1375; T. A. Martinek, F. Fülöp, Chem. Soc. Rev. 2012, 41, 687-702; P. G. Vasudev, S. Chatterjee, N. Shamala, P. Balaram, Chem. Rev. 2011, 111, 657-687; (f) J. P. Cole, A. M. Hanlon, K. J. Rodriguez, E. B. Berda, J. Polym. Sci., Part A: Polym. Chem. 2017, 55, 191-206; (g) S. H.Yoo and H.-S. Lee, Acc. Chem. Res., 2017, 50, 832-841; (h) K. L. George and W. S. Horne, Acc. Chem. Res., 2018, 51, 1220-1228. S. Fahs, Y. Patil-Sen and T. J. Snape, chemBioChem, 2015, 16, 1840-1853; R. Gopalakrishnan, A. I. Frolov, L. Knerr, W. J. Drury, E. Valeur, J. Med. Chem. 2016, 59, 9599-9621; J. W Checco and S. H Gellman, Curr. Opin. Struct. Biol. 2016, 39, 96-105.; C. Cabrele, T. A. Martinek, O. Reiser, L. Berlicki, J. Med. Chem. 2014, 57, 9718-9739; M. M. Muller, M. A. Windsor, W. C. Pomerantz, S. H. Gellman and D. Hilvert, Angew. Chem. Int. Ed. Engl., 2009, 48, 922-925; M. Nagano, M. Doi, M. Kurihara, H. Suemune, and M. Tanaka, Org. Lett., 2010, 12, 3564-3566; R. R. Araghi and B.Koksch, Chem. Comm. 2011, 47, 35443546; D. Becart, V. Diemer, A. Salaun, M. Oiarbide, Y. R. Nelli, B. Kauffmann, L. Fischer, C. Palomo and G. Guichard, J. Am. Chem. Soc., 2017, 139, 12524-12532; J. Aguesseau-Kondrotas, M. Simon, B. Legrand, J.L. Bantignies, Y.K. Kang, D. Dumitrescu, A. Van der Lee, J.M. Campagne, R.M. de Figueiredo, L.T. Maillard, Chemistry. 2019, 25(30):7396-7401 ; M.P. Del Borgo, K. Kulkarni, and M.-I. Aguilar, Aust. J. Chem., 2017, 70, 126-129; S. Kushida, O. Oki, H. Saito, J. Kuwabara, T. Kanbara, M. Tashiro, M. Katouda, Y. Imamura, Y. Yamamoto, J Phys Chem Lett., 2017, 8(18):4580-4586.

2 As selected reviews, see : (a) W. S. Horne and S. H. Gellman, Acc. Chem. Res., 2008, 41, 1399-1408; (b) P. G. Vasudev, S. Chatterjee, N. Shamala and P. Balaram, Chem. Rev., 2011, 111, 657-687; (c) T. A. Martinek and F. Fülöp, Chem. Soc. Rev., 2012, 41, 687-702.

3 (a) K. Kawasaki, M. Maeda, J. Watanabe and H. Kaneto, Chem. Pharm. Bull., 1988, 36, 1766-1771; (b) J-M. Kim, Y. Bi, S. J. Paikoff and P. G. Schultz, Tetrahedron Lett., 1996, 37, 5305-5308; (c) K. Burgess, J. Ibarzo, D. S. Linthicum, D. H. Russel, H. Shin, A. Shitangkoon, R. Totani and A. J. Zhang, J. Am. Chem. Soc., 1997, 119, 1556-1564; (d) A. Boeijen and R. M. J. Liskamp, Eur. J. Org. Chem., 1999, 2127-2135; (e) V. Semetey, D. Rognan, C. Hemmerlin, R. Graff, J-P. I. Briand, M. Marraud and G. Guichard, Angew. Chem. Int. Ed., 2002, 41, 1893-1895; (f) A. Violette, M. C. Averlant-Petit, V. Semetey, C. Hemmerlin, R. Casimir, R. Graff, M. Marraud, J. P. Briand, D. Rognan and G. Guichard, J. Am. Chem. Soc., 2005, 127, 2156-2164; (g) L. Fischer, C. Didierjean, F. Jolibois, V. Semetey, J. M. Lozano, J. P. Briand, M. Marraud, R. Poteau and G. Guichard, Org. Biomol. Chem., 2008, 6, 2596-2610; (h) L. Fischer, P. Claudon, N. Pendem, E. Miclet, C. Didierjean, E. Ennifar and G. Guichard, Angew. Chem. Int. Ed., 2010, 49, 1067-1070; (i) L. Fischer and G. Guichard, Org. Biomol. Chem., 2010, 8, 3101-3117.

4 (a) P. Claudon, A. Violette, K. Lamour, M. Decossas, S. Fournel, B. Heurtault, J. Godet, Y. Mely, B. Jamart-Gregoire, M. C. AverlantPetit, J. P. Briand, G. Duportail, H. Monteil and G. Guichard, Angew. Chem. Int. Ed., 2010, 49, 333-336; (b) Y. R. Nelli, L. Fischer, G. W. Collie, B. Kauffmann and G. Guichard, Biopolymers, 2013, 100, 687-697; (c) N. Pendem, Y. R. Nelli, C. Douat, L. Fischer, M. Laguerre, E. Ennifar, B. Kauffmann and G. Guichard, Angew. Chem. Int. Ed., 2013, 52, 4147-4151.

5 For selected examples, see: (a) D. H. Appella, L. A. Christianson, D. A. Klein, D. R. Powell, X. Huang, J. J. Barchi and S. H. Gellman, Nature (London), 1997, 387, 381-384; (b) T. L. Raguse, E. A. Porter, B. Weisblum and S. H. Gellman, J. Am. Chem. Soc., 2002, 124, 12774-12785; (c) N. Rathore, S. H. Gellman and J. J. de Pablo, Biophys. J., 2006, 91, 3425-3435; (d) E. Vaz, W. C. Pomerantz, M. Geyer, S. H. Gellman and L. Brunsveld, ChemBioChem, 2008, 9, 2254-2259; (e) A. Hetényi, Z. Szakonyi, I. M. Mandity, E. Szolnoki, G. K. Toth, T. A. Martinek and F. Fülöp, Chem. Commun., 2009, 177-179; (f) L. Guo, W. Zhang, A. G. Reidenbach, M. W. Giuliano, I. A. Guzei, L. C. Spencer and S. H. Gellman, Angew. Chem. Int. Ed., 2011, 50, 5843-5846; (g) H. Awada, C. M. Grison, F. CharnayPouget, J-P. Baltaze, F. Brisset, R. Guillot, S. Robin, A. Hachem, N. Jaber, D. Naoufal, O. Yazbeck and D. J. Aitken, J. Org. Chem., 2017, 82, 4819-4828.

6 (a) O. Songis, C. Didierjean, C. Laurent, J. Martinez and M. Calmes, Eur. J. Org. Chem., 2007, 3166-3172; (b) C. André, B. Legrand, C. Deng, C. Didierjean, G. Pickaert, J. Martinez, M. C. Averlant-Petit, M. Amblard and M. Calmes, Org. Lett., 2012, 14, 960-963.

7 B. Legrand, C. André, E. Wenger, C. Didierjean, M. C. Averlant-Petit, J. Martinez, M. Calmes and M. Amblard, Angew. Chem. Int. Ed., 2012, 51, 11267-11270.

8 N. Pendem, C. Douat, P. Claudon, M. Laguerre, S. Castano, B. Desbat, D. Cavagnat, E. Ennifar, B. Kauffmann and G. Guichard, J. Am. Chem. Soc., 2013, 135, 4884-4892.

9 The use of a chiral cis-1,2-diaminocyclohexane unit has been also reported as a screw-sense controller of helical conformation of achiral acyclic homo-oligoureas (hAib derivatives). R. Wechsel, J. Maury, J. Fremaux, S.P. France, G. Guichard and J. Clayden, Chem. Commun. 2014, 50, 15006-15009.

10 C. André, B. Legrand, L. Moulat, E. Wenger, C. Didierjean, E. Aubert, M. C. Averlant-Petit, J. Martinez, M. Amblard and M. Calmes, Chem. Eur. J., 2013, 19, 16963-16971.

11 P. Milbeo, L. Moulat, C. Didierjean, E. Aubert, J. Martinez and M. Calmès, J. Org. Chem., 2017, 73, 3144-3151.

12 V. Semetey, C. Hemmerlin, C. Didierjean, A. P. Schaffner, A. G. Giner, A. Aubry, J. P. Briand, M. Marraud and G. Guichard, Org. Lett., $2001,3,3843-3846$. 